\title{
PHYSICAL PROPERTIES OF SECOND GENERATION BIOETHANOL FUEL MADE FROM BREM WASTE
}

\author{
Indah Puspitasari ${ }^{1}$, Nanang Romandoni ${ }^{2}$ \\ ${ }^{1,2}$ Teknik Mesin Otomotif, Politeknik Negeri Madiun, Jl. Serayu No.84 Kota Madiun 63133, \\ Telp. (0351)452970 Fax (0351)452960 \\ Email : ${ }^{1}$ indahpuspitasari@pnm.ac.id, ${ }^{2}$ nanang@pnm.ac.id
}

\begin{abstract}
Second generation bioethanol fuels are made from the vegetable material containing cellulose and lignin which is generally a solid agro-industrial waste biomass. Biomass waste has a considerable amount in Indonesia. One of them is waste from the brem food processing industry in Caruban Madiun. Bioethanol is potential to be utilized as motor vehicle fuel with a requirement of $99.5 \%$ purity and has properties corresponding to the standard of denatured bioethanol for gasohol. This research was conducted by experimental method, which is making second generation bioethanol fuel from the waste of brem in laboratory scale. The initial stage is hydrolysis and then fermentation process by using saccharomyces cerevisiae yeast with a variation of fermentation length, yeast weight, and water volume. The next process is distillation stage one, distillation of stratum, and dehydration by adding salt and silica gel. The optimal bioethanol is then blended with pertalite and tested for octane value characteristics. The results of this study obtained the best comparison of 250 grams of brem waste, 1250 $\mathrm{ml}$ of water, 10 grams of yeast tape, and 5 days of fermentation time with 93\% alcohol content. From the alcohol content, the characteristics of the mixture of pertalite and bioethanol were obtained. The result of octane value was E5 which was 100.8; E10 is 101.3; and E15 equal to 106.8. The more a mixture of bioethanol with pertalite, the greater the octane value.
\end{abstract}

Keywords: second generation bioethanol, alternative fuels, brem waste, standard of denatured bioethanol for gasohol

\begin{abstract}
ABSTRAK
Bioetanol generasi kedua adalah bioetanol dari bahan nabati yang mengandung selulosa dan lignin yang umumnya merupakan biomassa limbah padat agroindustri. Limbah biomassa mempunyai jumlah cukup besar di Indonesia. Salah satunya adalah limbah dari industri pengolahan makanan brem di Caruban Madiun. Bioetanol potensial untuk dimanfaatkan sebagai bahan bakar kendaraan bermotor dengan syarat memiliki kadar kemurnian 99,5\% dan mempunyai properties yang sesuai dengan standart mutu bioetanol terdenaturasi untuk gasohol. Penelitian ini dilakukan dengan metode eksperimental, yaitu membuat bioetanol generasi kedua dari limbah ampas brem skala laboratorium. Tahap awal adalah hidrolisa, kemudian fermentasi dengan menggunakan ragi Saccharomyces cereviceae dengan variasi penelitian yaitu lama fermentasi, berat ragi dan volume air. Proses berikutnya adalah distilasi dan distilasi bertingkat serta dehidrasi dengan menambahkan garam dan silica gel. Bioetanol paling optimal selanjutnya diblending dengan pertalite dan diuji karakteristik nilai oktan. Hasil dari penelitian ini didapatkan perbandingan terbaik yaitu $250 \mathrm{gr}$ limbah ampas brem, $1250 \mathrm{ml}$ air, 10 gr ragi tape, dan lama waktu fermentasi 5 hari dengan kadar alkohol 93\%. Dari kadar alkohol tersebut dilakukan uji karakteristik campuran pertalite dan bioethanol didapat hasil nilai oktan yaitu E5 sebesar 100,8; E10 sebesar 101,3; dan E15 sebesar 106,8. Semakin banyak campuran bioetanol dengan pertalite maka nilai oktan semakin besar.
\end{abstract}

Kata kunci : bioetanol generasi kedua, bahan bakar alternatif, limbah ampas brem

\section{PENDAHULUAN}

Brem merupakan salah satu makanan tradisional hasil fermentasi yang enak dan bergizi yang banyak di produksi di Jawa Timur dan Jawa Tengah. Di Jawa Timur, sentra pengolahan brem terdapat di Madiun yaitu di Desa Kaliabu
Kecamatan Mejayan yang memiliki banyak industri pengolahan ketan hitam menjadi brem. Menurut data Badan Pusat Statistik Kabupaten Madiun yang bersumber dari Dinas Koperasi, Perindustrian, Perdagangan dan Pariwisata Kabupaten Madiun, pabrik 
pengolahan brem di Madiun seluruhnya ada 51 home industry dengan total produksi sekitar 1-3 ton per hari. Dalam pembuatan makanan brem, dari bahan dasar yang dibuat, hanya sekitar 30\% yang berhasil menjadi makanan brem. Sedangkan sisanya 70\% menjadi limbah yang berupa air dan ampas brem padat (Anisa dan Walujo, 2014).

Menurut IA Sinta Citra Pertiwi, dkk (2016) mmpas brem tersebut diketahui masih memiliki kandungan pati dan selulosa yang cukup tinggi. Ampas padat brem yang telah diolah menjadi tepung ampas brem mempunyai kadar air sebesar 9,20\%, kadar abu 0,76\%, kadar protein 15,62\%, kadar lemak 7,12\%, serat kasar sebesar 2,76\%, dan kadar karbohidrat sebesar $67,30 \%$ yang dihitung dengan by difference. Senyawa- senyawa tersebut merupakan komponen utama dari bioetanol generasi kedua. Dengan demikian, limbah ampas brem sangat berpotensi untuk diolah menjadi bioetanol generasi kedua yang selanjutnya dapat digunakan sebagai bahan bakar alternatif ramah lingkungan.

Menurut Badan Standarisasi Nasional, BSN (2008), bioetanol potensial untuk dimanfaatkan sebagai bahan bakar kendaraan bermotor apabila sudah diolah menjadi fuelgrade ethanol dengan syarat bioetanol memiliki kadar kemurnian 99,5\%. Syarat tersebutmutlak karena jika berkadar di bawah 90\%, maka mesin tidak dapat menyala bahkan dapat menimbulkan kerusakan alat karena kandungan airnya terlampau tinggi. Selain itu, syarat untuk menjadi bahan bakar kendaraan bermotor, karakteristrik dari bioetanol harus sesuai dengan standart mutu bioetanol terdenaturasi untuk gasohol. Oleh karena itu diperlukan uji properties bioetanol generasi kedua dari limbah ampas brem agar bisa diketahui karakteristiknya untuk dapat dimanfaatkan menjadi bahan bakar alternatif ramah lingkungan sebagai salah satu langkah untuk ikut mensukseskan program pemerintah yaitu substitusi BBM dengan bioetanol.

Tujuan dari penelitian ini adalah untuk mengevaluasi pengaruh lama waktu fermentasi, berat ragi, dan volume air dalam proses pembuatan bioetanol generasi kedua dari limbah brem terhadap kadar bioetanol. Bioetanol yang kadarnya paling optimal selanjutnya akan diblending dengan pertalite dan diuji karakteristik nilai oktannya agar dapat disesuaikan dengan kondisi mesin kendaraan.

\section{METODE PENELITIAN}

Penelitian dilakukan di Laboratorium Teknik Pembakaran dan Bahan Bakar Politeknik Negeri Madiun. Variabel bebas pada penelitian ini adalah memvariasi perbandingan berat limbah ampas brem terhadap lama waktu fermentasi (3, 5, 7 hari), berat ragi (8, 10, dan 12 gram), dan volume air (750, $\mathrm{ml}, 1250 \mathrm{ml}$, dan $1750 \mathrm{ml}$ ).

Variabel terikat dapat disebut hasil atau objek penelitian, yaitu kadar bioetanol dan nilai oktan campuran bioetanol dengan pertalite (E5, E10, E15). Variabel kontrol merupakan usaha untuk menghilangkan pengaruh variabel - variabel selain variabel bebas yang mempengaruhi hasil variabel terkait. Variabel kontrol dalam penelitian ini yaitu ragi yang digunakan dalam proses fermentasi adalah ragi tape (Saccharomyces cereviceae), berat limbah ampas brem tetap yaitu 250 gr, dilakukan penambahan garam dan silica gel pada distilasi bertingkat, temperature pada proses distilasi $78^{\circ} \mathrm{C}$.

Berikut prosedur pembuatan yang akan dilaksanakan pada proses pembuatan yang dijabarkan secara singkat:Proses hidrolisa, proses ini bertujuan memecah polimer menjadi molekul yang kecil dan mengubah karbohidrat menjadi gula sederhana.

Berikut adalah proses hidrolisa: 
1) Pengumpulan bahan baku limbah ampas brem

2) Mencampurkan bahan baku dengan air yaitu $750 \mathrm{ml}, 1250 \mathrm{ml}, 1750 \mathrm{ml}$

3) Penghancuran bahan baku limbah ampas brem menggunakan blender agar penghancuran sempurna dan dapat menghasilkan gula/karbohidrat agar dapat mudah dalam proses fermentasi. Limbah ampas brem dapat dilihat pada gambar 1 .

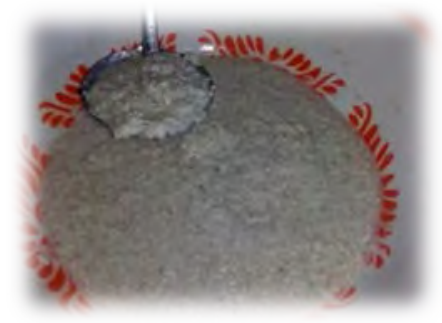

Gambar 1. Ampas brem

Sumber: Dokumentasi, 2018

Proses berikutnya adalah fermentasi, yaitu proses produksi energi sel dalam keadaan tanpa oksigen. Dibawah ini adalah proses fermentasi:

1) Menyiapkan jirigen 10 liter sampai 20 liter untuk tempat fermentasi.

2) Merebus ampas brem selama kurang lebih 10 menit.

3) Setelah dingin campur bahan dengan ragi saccharomyces (ragi tape) sesuai dengan takar yaitu 8 gr, 10 gr, 12 gr

4) Memasukan kedalam jirigen yang dikeluarkan udaranya terlebih dahulu lalu tutup rapat jirigen dan pastikan tidak ada udara yang masuk.

5) Jika jirigen sudah kembali keukuran semula atau telah memenuhi syarat hari yaitu 3 hari, 5 hari, 7 hari, maka buka jirigen lalu saring dan peras hasil fermentasi agar terpisah dari ampas dan cairan.

Proses selanjutnya distilasi yaitu bertujuan untuk memisahkan kandunganbioethanoldengan air hasil fermentasi limbah ampas brem berdasarkan titik didihnya. Alat distilasi dapat dilihat pada gambar 2 .

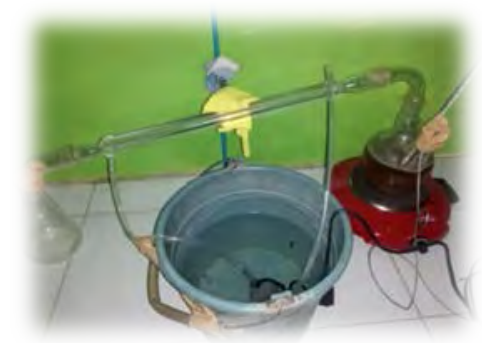

Gambar 2. Proses distilasi

Sumber: Dokumentasi, 2018

Yang dilakukan pada proses distilasi diantaranya :

1) Memasang thermocontrol pada kompor listrik untuk mengatur suhu

2) Menyiapkan labu distilasi dengan kapasitas $1000 \mathrm{ml}$ dan labu penampung hasil destilasi

3) Memasang thermocouple pada labu distilasi

4) Memasang condensor liebig sebagai pendingin pada proses penguapan. Pada condensor liebig dipasang selang yang telah dialiri air untuk mempercepat pendinginan.

5) Limbah ampas brem disaring dan menghasilkan air hasil fermentasi kurang lebih $750 \mathrm{ml}$ dimasukkan ke dalam labu distilasi.

6) Proses distilasi dimulai dengan memanaskannya pada suhu $78^{\circ} \mathrm{C}$ sesuai titik didih bioethanol.

7) Mengukur kadar bioethanol hasil destilasi dengan menggunakan alcoholmeter.

8) Untuk proses pengujian karakteristik bioethanol maka proses distilasi harus mencapai kadar bioethanol di atas $90 \%$.

9) Dalam penelitian ini dibutuhkan tiga kali atau lebih pengulangan proses destilasi untuk mendapatkan kadar bioethanol di atas $90 \%$.

10) Langkah berikutnya adalah distilasi kedua. Langkah yang dilakukan hampir sama dengan proses distilasi pertama, namun ada sedikit tambahan supaya diperoleh kadar bioethanol lebih maksimal. Tambahan tersebut adalah dengan menambahkan garam dan silika gel 
ke dalam proses distilasi. Silika gel yang dipasang diantara gelas labu dengan condensor liebig ini berfungsi sebagai penyerap kelembaban air. Dengan demikian hasil pada proses distilasi kedua ini akan menghasilkan kadar bioethanol yang lebih tinggi dari pada proses distilasi pertama.

11) Hal ini juga dilakukan pada distilasi ketiga maupun seterusnya.

Pengujian yang dilakukan pertama kali adalah mengukur kandungan alkohol pada bioethanoldengan menggunakan alat alkohol meter. Pada bagian atas alkohol meter dilengkapi dengan skala yang menunjukkan kadar alkohol. Seperti yang ditunjukan pada gambar 3. Prinsip kerjanya berdasarkan berat jenis campuran antara alkohol dan air. Pertama memasukan bioethanolke dalam gelas ukur atau tabung atau botol yang tingginya lebih panjang dari alkohol meter. Kemudian memasukan batang alkohol meter ke dalam gelas ukur. Alkohol meter akan tenggelam dan batas air akar menunjukan berapa kandungan alkohol meter di dalam larutan. Bioethanolyang dapat diukur dengan alkohol meter adalah bioethanolyang sudah didistilasi.

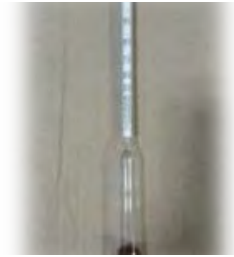

Gambar 3. Alcohol meter

Sumber: Dokumentasi, 2018

Pengujian karakteristik bioethanolyang akan dilakukan adalah pengujian nilai oktan. Untuk mengetahui nilai oktan dilakukan pengujian di Laboratorium Lanud Iswahjudi, Magetan, dapat dilihat pada gambar 4 .

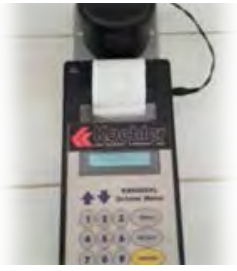

Gambar 4. Octane meter

Sumber: Dokumentasi, 2018

Setelah melakukan metode pengujian di laboratorium terkait maka akan terdapat hasil dari nilai oktan. Hal ini agar dapat dijadikan acuan untuk bagian mesin agar disesuaikan dengan bahan bakar dari limbah ampas brem untuk kendaraan roda dua.

\section{HASIL dan PEMBAHASAN}

Penelitian pertama yang dilakukan yaitu mencari parameter waktu fermentasi yang optimal dengan variasi waktu 3, 5 dan 7 hari menggunakan berat ragi 10 gr, volume air $1250 \mathrm{ml}$ dan berat limbah ampas brem 250 gr. Data kadar bioethanolhasil distilasi berdasarkan lama waktu fermentasi ditunjukkan seperti pada gambar 5 berikut:

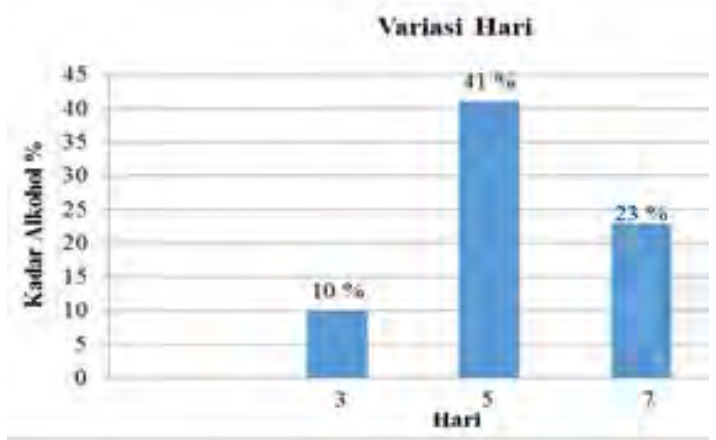

Gambar 5. Kadar bioethanol berdasarkan lama waktu fermentasi

Berdasarkan Gambar 5 terlihat bahwa untuk perbandingan ragi 10 gr dengan lama waktu fermentasi 3 hari dan volume air $1250 \mathrm{ml}$ menghasilkan kadar bioethanol sebesar 10\%, sedangkan untuk lama waktu fermentasi 5 hari mengalami peningkatan dengan kadar bioethanol sebesar 41\%, untuk lama waktu 7 hari mengalami penurunan dengan kadar bioethanolsebesar 23\%. 
Dengan demikian dengan perbandingan 250 gr limbah ampas brem, $1250 \mathrm{ml}$ air dan ragi 10 gr menghasilkan kadar bioethanolyang optimal sebesar $41 \%$ dengan lama waktu fermentasi 5 hari.

Penelitian yang kedua mencari berat ragi. Setelah didapat hasil lama waktu fermentasi dengan menghasilkan kadar bioethanol yang maksimal maka hasil tersebut selanjutnya akan dijadikan parameter untuk mencari berat ragi, dengan memvariasi berat ragi masingmasing 8 gr,10 gr dan 12 gr.

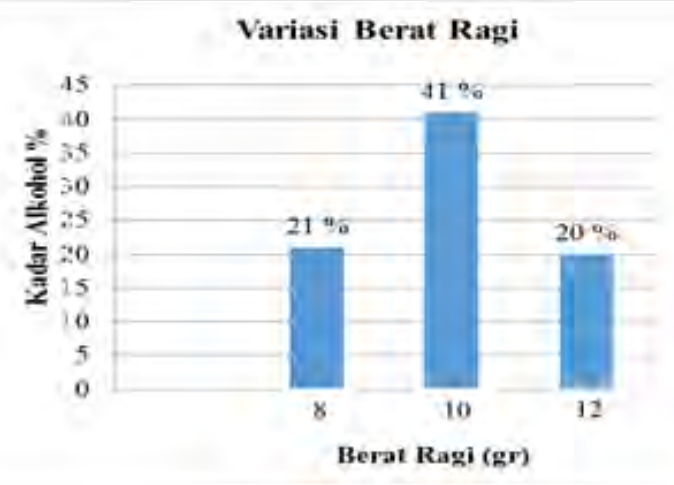

Gambar 6. Kadar bioethanol berdasarkan berat ragi

Berdasarkan gambar 6 terlihat bahwa untuk perbandingan ragi 10 gram dengan lama waktu fermentasi 5 hari dan air $1250 \mathrm{ml}$ menghasilkan kadar bioethanol 41\%, sedangkan untuk perbandingan ragi 8 gr, dan 12 gr mengalami penurunan dengan kadar bioethanol masing-masing 21\%, dan 20\%. Dengan demikian untuk perbandingan 250 gr limbah ampas brem, air $1250 \mathrm{ml}$ dan ragi $10 \mathrm{gr}$ menghasilkan kadar bioethanol yang lebih maksimal yaitu $41 \%$.

Lama hari dan berat ragi untuk fermentasi dengan hasil yang maksimal sudah didapatkan kemudian hasil tersebut akan dijadikan parameter untuk mencari perbandingan volume air, dengan volume perbandingan air masing-masing $750 \mathrm{ml}, 1250 \mathrm{ml}$, dan1750 ml.

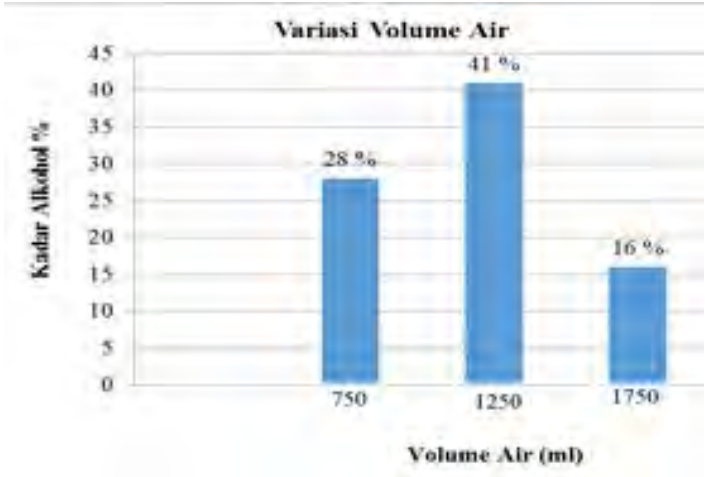

Gambar 7. Kadar bioethanol berdasarkan volume air

Berdasarkan gambar 7 terlihat bahwa untuk perbandingan ragi 10 gram dengan lama waktu fermentasi 5 hari dan air $1250 \mathrm{ml}$ menghasilkan kadar bioethanol 41\%, sedangkan untuk perbandingan air $750 \mathrm{ml}$ dan $1750 \mathrm{ml}$ mengalami penurunan dengan kadar bioethanol masing-masing 28\%, dan $16 \%$. Dengan demikian untuk perbandingan 250 gr limbah ampas brem, air $1250 \mathrm{ml}$ dan ragi $10 \mathrm{gr}$ menghasilkan kadar bioethanol yang lebih maksimal yaitu $41 \%$.

Kadar bioethanoldari limbah ampas brem yang digunakan untuk bahan bakar lebih dari 90\%. Dalam pembuatan bioethanol bertingkat membuat komposisi 10 kali lebih besar yaitu 2500 gr limbah ampas brem, $12500 \mathrm{ml}$ air dan 100 gr ragi. Dalam pembuatan bioethanol bertingkat menggunakan alat distilasi yang berkapasitas 1 liter. Distilasi pertama dibutuhkan waktu 1 bulan, delapan kali pergantian air fermentasi menghasilkan bioethanol $1500 \mathrm{ml}$ dengan kadar 41\%. Distilasi kedua dibutuhkan waktu 21 hari, tiga kali distilasi dan menghasilkan bioethanol980 ml. Distilasi bertingkat yang ketiga dibutuhkan waktu 10 hari dan menghasilkan bioethanol $500 \mathrm{ml}$. Untuk menaikkan kadar bioethanol membutuhkan 3 kali distilasi dengan penambahan garam dan juga silica gel. Berikut ini adalah tabel presentase kenaikan bioethanolhasil distilasi 
bertingkat yang ditunjukkan dalam tabel 1.

Tabel 1. Hasil distilasi bertingkat limbah ampas brem

\begin{tabular}{ccc}
\hline Distilasi & $\begin{array}{c}\text { Volume } \\
\text { Bioethanolyang } \\
\text { dihasilkan (ml) }\end{array}$ & $\begin{array}{c}\text { Kadar } \\
\text { Bioethanol(\%) }\end{array}$ \\
\hline $\begin{array}{c}\text { Distilasi } \\
1\end{array}$ & 1500 & 41 \\
\hline $\begin{array}{c}\text { Distilasi } \\
2\end{array}$ & 980 & 73 \\
\hline $\begin{array}{c}\text { Distilasi } \\
3\end{array}$ & 500 & 93 \\
\hline
\end{tabular}

Berdasarkan gambar 8 menunjukkan hasil bahwa 2500 gr limbah ampas brem menghasilkan $500 \mathrm{ml}$ bioethanol dengan kadar 93\% diperoleh dari hasil distilasi ketiga.

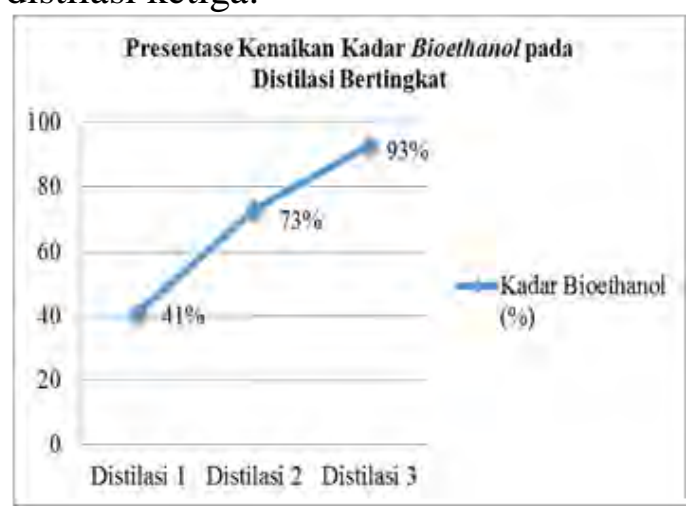

Gambar 8. Hasil distilasi bertingkat

Hasil bioethanol paling optimal kemudian diblending dengan pertalite dengan rasio campuran E5, E10, E15 dan E20 dan diuji nilai oktan menggunakan alat octane meterdi Laboratorium Lanud Iswahjudi Magetan, Jawa Timur.

Tabel 2. Hasil uji nilai oktan campuran pertalite dan bioethanollimbah ampas brem

\begin{tabular}{cccc}
\hline No. & $\begin{array}{c}\text { Pertalite } \\
(\%)\end{array}$ & Bioethanol(\%) & $\begin{array}{c}\text { Nilai } \\
\text { Oktan }\end{array}$ \\
\hline 1. & 95 & 5 & 100.8 \\
\hline 2. & 90 & 10 & 101.3 \\
\hline 3. & 85 & 15 & 106.8 \\
\hline 4. & 80 & 20 & - \\
\hline
\end{tabular}

Pengujian nilai oktan tidak bisa dilakukan apabila menggunakan bioethanolmurni karena alat octane meter hanya bisa mengukur yang nilai oktannya $100 \pm 10$ sedangkan nilai oktan murni yang terdapat pada bioethanol \pm 118 . Tabel 2 menunjukkan bahwa nilai oktan untuk E5 adalah 100,8; nilai oktan E10 adalah 101,3; nilai oktan E15 adalah 106,8 dan nilai oktan E20 tidak terbaca pada octane meterdikarenakan nilai oktannya diprediksi melebihi 110 .

\section{KESIMPULAN}

Berdasarkan analisa hasil dari pembahasan di atas maka dapat disimpulkan beberapa hal sebagai berikut yaitu variasi yang menghasilkan kadar bioethanol paling optimal untuk pembuatan bioethanol dari limbah ampas brem adalah 250 gr limbah ampas brem dengan volume air $1250 \mathrm{ml}$ serta penambahan ragi sebanyak 10 gram kemudian lama fermentasi 5 hari. Distilasi pertama menghasilkan kadar bioethanol $41 \%$, proses distilasi yang kedua dan ketiga dengan penambahan garam dan silica gel menghasilkan kadar bioethanol 73\% dan 93\%. Hasil pengujian karakteristik nilai oktan dari campuran pertalite dan bioethanol limbah ampas brem yaitu 5\% bioethanol menghasilkan nilai oktan 100.8, 10\% bioethanol 101.3, 15\% bioethanol menghasilkan nilai oktan 106.8. Untuk penelitian berikutnya, bioethanol dapat diaplikasikan pada kendaraan bermotor dengan beberapa modifikasi kemudian diuji performa mesin dan emisi gas buang.

\section{UCAPAN TERIMAKASIH}

Penulis mengucapkan terima kasih kepada Direktorat Riset dan Pengabdian Masyarakat Kementerian Riset, Teknologi, dan Pendidikan Tinggi yang telah membiayai pengabdian 
masyarakat melalui skema Penelitian Dosen Pemula (PDP) Tahun 2018.

\section{DAFTAR PUSTAKA}

[1] IA Sinta Citra Pertiwi, LP Wrasiati, IWArnata. 2016. Pemanfaatan Ampas Padat Brem Cair Menjadi Gula Cair. Jurnal Rekayasa dan Manajemen Agroindustri, Universitas Udayana. Vol 4, No 4, Desember 2016 : 49 - 58 .

[2] N. Anisa dan SA. Walujo. 2014. Bioethanol Ampas Brem sebagai Sumber Bahan Bakar Terbarukan. Jurnal Saintek Kopertis Wilayah VII, Vol. 11, No. 1 Juni 2014: 44-49.

[3] Prihandana, Rama, Kartika Noerwijan, dkk. 2007. Bioetanol Ubi kayu; bahan Bakar Masa Depan. Agromedia Pustaka. Jakarta.

[4] Supraptono, 2004, Bahan Bakar dan Pelumas, Teknik Mesin Fakultas Teknik Universitas Negeri Semarang. 
Indah Puspitasari dan Nanang Romandoni, Physical Properties of Second..... 